\title{
COST MEASUREMENTS IN PRODUCTION AND DELIVERY OF A MASSIVE OPEN ONLINE COURSE (MOOC) FOR TEACHING THE RELATIONSHIP BETWEEN HUMAN HEALTH AND CLIMATE CHANGE: A CASE STUDY
}

\author{
Edward Meinert ${ }^{1,2}$, Michelle van Velthoven ${ }^{1}$, Abrar Alturkistani ${ }^{2}$, Kris A Murray ${ }^{3}$, \\ Philippe Sabatier ${ }^{4}$ and Josip Car $^{2}$ \\ ${ }^{1}$ University of Oxford, Digitally Enabled PrevenTative Health (DEPTH) Research Group, Department of \\ Paediatrics, Oxford OX3 9DU, United Kingdom \\ ${ }^{2}$ Imperial College London, Global Digital Health Unit, Department of Primary Care and Public Health, \\ School of Public Health, London W6 8RP, United Kingdom \\ ${ }^{3}$ Imperial College London, MRC Centre for Global Infectious Disease Analysis, School of Public Health, \\ London W6 8RP, United Kingdom \\ ${ }^{4}$ Université Grenoble Alpes, 621 avenue Centrale 38400 Saint-Martin-d'Hères, France
}

\begin{abstract}
A Massive Open Online Course (MOOC) is a form of online education that makes available learning to a large number of individuals at no charge. The impact of climate change on public health has been introduced in MOOCs in various forms, for example, examining the impact of natural disasters, the increase in temperature on work productivity, and the monitoring and evaluation of health adaptation to climate change and its implications for policy. However, despite this work completed to advance understanding in both online and postgraduate education, more effort is required to provide the tools and capabilities to analyse evidence and present findings that demonstrate its impact on specific outcomes, including health and wellbeing. Although these courses are made publicly available, understanding the costs associated with their production and delivery will provide evidence to develop sustainable models for deployment of this form of citizen engagement education.
\end{abstract}

\section{KEYWORDS}

Education (MeSH), Education, Distance (MeSH), Education, Professional (MeSH), Online Education, Online Learning, Costs and Cost Analysis (MeSH), Economics (MeSH) 


\section{COST MEASUREMENTS IN PRODUCTION AND DELIVERY OF A MASSIVE OPEN ONLINE COURSE (MOOC) FOR TEACHING THE RELATIONSHIP BETWEEN HUMAN HEALTH AND CLIMATE CHANGE: A CASE STUDY}

\section{INTRODUCTION}

Climate change is already having a negative impact on human health through direct and indirect effects and is considered one of the most significant public health challenges for the 21st century (Watts et al., 2018, pp. 2479-2514; Wuebbles et al., 2017, p. 669). Modifiable environmental factors are causing an estimated $23 \%$ of worldwide mortality and $26 \%$ of deaths in children younger than five years (World Health Organisation, 2016). While the 21st Conference of the Parties (COP21) and the subsequent Paris Agreement represent critical international progress towards tackling this global threat, the world remains off target in terms of reducing emissions to the extent required to limit warming to 'well below $2 \mathrm{C}$ ' and implement adaptation plans to help meet the challenge of present and future impacts. There is thus a continuing and growing need for active citizen engagement and education on to help facilitate the technological and social transitions required across sectors if global targets to limit warming and manage impacts are to be achieved (Glanz, Rimer, \& Viswanath, 2008).

A Massive Open Online Course (MOOC) is a form of online education that makes available learning to a large number of individuals at no charge (Veletsianos \& Shepherdson, 2016). Knowledge related to health behaviours has rapidly increased over the last two decades, and a dynamic interaction between learners and educators has the potential to improve environmental outcomes as well as individual and population-based health outcomes (Glanz, Rimer, \& Viswanath, 2008). The impact of climate change on public health has been introduced in MOOCs in various forms, for example, examining the impact of natural disasters, the increase in temperature on work productivity, and the monitoring and evaluation of health adaptation to climate change and its implications for policy (Milligan, Littlejohn, \& Margaryan, 2013). However, despite this work completed to advance understanding in both online and postgraduate education, more effort is required to provide the tools and capabilities to analyse evidence and present findings that demonstrate climate change's impact on target outcomes, including health and wellbeing.

A principal aim of an MOOC focused on the relationship between climate change and public health is to allow citizens to have a critical awareness of the key issues and to possibly inspire a new generation of actors who can help address the challenges. This includes climate scientists who will develop skills in integrating both public health and data science or health professionals able to catalyse the incorporation of climate change impacts into public health policies. Education helps learners to make informed decisions and build communities of practice centred on these issues, thereby strengthening, in the long run, resilience to climate change. Such democratisation of science and enhancement of societal relations may be achieved through engagement of the public in debate on issues and governmental decision-making (Swim, Clayton, Doherty et al, 2009). Digital learning has been shown to be more efficient than traditional learning approaches in promoting achievement and motivation in learners (Smeda, Dakich, \& Sharda 2014). Therefore, challenges in communicating the public health implications of climate change may be addressed through the application of digital learning in the climate change and health education agenda.

The MOOC field is new territory, and evaluating MOOCs is even newer. The novel combination of teaching approaches used, including pre-recorded videos, live discussion forums, peer-assessed assignments, and social media debate, warrant thorough investigation to enable providers to maximize participation and impact (Perris, 2015). It is vital that appropriate methods are used to determine the impact of these courses. Although these courses 
IADIS International Journal on WWW/Internet

are made publicly available, understanding the costs associated with their production and delivery will provide evidence to develop sustainable models for deployment of this form of citizen engagement education (Joshi \& Perin, 2012). The literature suggests that a benefit of Web-based learning is its cost-effectiveness compared with face-to-face instruction. However, there is limited evidence validating comparison with other forms of instruction or standards for the budgeting of the costs in the production and execution of e-Learning courses (Meinert et al., 2019). There is limited evidence on the costs associated with the production of MOOCs (Hollands \& Tirthali, 2014), whilst the costs to develop a high quality MOOC are considerable.

The aims and objectives of this study intend to address a gap in the research literature concerning implementation details on planning and executing MOOCs (Meinert et al., 2019). In addition to limited cost-centered studies, there are few details on how course designers and producers are calculating the associated costs for production of these course types. The purpose of this study was to determine how the total costs for the production and delivery of an MOOC are calculated and the factors that influence the production and development of an open-access course. The focus here is identification of the direct and indirect costs in implementation, which then allows the execution of further economic evaluation. This approach will allow course designers and implementers to leverage knowledge gained from this case study to better plan and manage future implementations, which will also create a reusable framework to apply cost planning. This work will demonstrate the effect in pre-implementation budget management against the proposed framework and should result in better course planning.

\subsection{Objectives}

1. Identification of the components or 'ingredients' for the production and delivery of an MOOC to form a comprehensive project budget

2. Use of a variance calculation of the ingredients for the cost of production and delivery of an MOOC

3. Explore the factors that have an impact on the planning of costs for eLearning delivery.

\section{STUDY OVERVIEW}

The MOOC instructional design was focused on connectivist learning theory, where networking and skill acquisition will be enhanced through the development of sustainable peer learning and engagement in a peer-to-peer concept (Milligan et al., 2013). Through enhancement of information flow and exchange, the MOOC instructional design was centred on building online social networks promoting collaborations and discussion between learners and various stakeholders. Consequently, stakeholders were engaged in the learning process whilst developing digital skills. By virtue of challenge-based learning, learners were informed on national and regional health-climate-related issues. Through an increase in awareness and participation of local communities, the educational platform was designed to empower citizens with informed decision-making skills thereby leading to, inter alia, European economic prosperity. In addition to expanding the proportion of people aware of the MOOC through use 


\section{COST MEASUREMENTS IN PRODUCTION AND DELIVERY OF A MASSIVE OPEN ONLINE COURSE (MOOC) FOR TEACHING THE RELATIONSHIP BETWEEN HUMAN HEALTH AND CLIMATE CHANGE: A CASE STUDY}

of social media, the establishment of networks was designed to enable a deeper understanding of the target population. Additionally, a post-course collaboration between stakeholders was to be promoted, thereby improving sustainability and positive impacts of the course and maintaining citizen engagement.

The course was developed from July through October 2017 and delivered to participants from November to December 2017. The course was produced as a consortium including Imperial College London, University Grenoble Alpes, and the European Institute of Innovation and Technology - Climate Knowledge Innovation Community Video Production Team.

\subsection{Methods}

\subsubsection{Study Design}

The study focused on analysing the variance of the cost of production of a massive open online course. The study design employed a case study design for production course observation of financial decision making and cost analysis to understand variances in production costs to budgeted costs. The study made modifications to a study protocol executed by the research team in the previous year, to gather further evidence concerning production cost variance in online learning (Meinert, Eerens, Banks, \& Car, 2019). While that study was focused on a Small Private Online Course (SPOC), this course would focus on the broader learner engagement management of an open-access course. Ethical approval for the study was obtained through the Imperial College Education Ethics Research Committee (EERP1617-030).

\subsubsection{Methodological Framework}

A case study research design was selected because the study would not introduce changes to the way in which the course was designed and therefore strictly focus on the financial actions taken in the production and development of the course. The objective of the case study is to inform the way future costs are budgeted in the development of a MOOC. The research forms part of a broader investigation into the costs associated with course production; the main focus was to collect primary evidence in the construction of these costs to allow for further research comparing results with other Web-based learning implementation types.

Existing research indicates challenges in the capture of total costs for the production of Web-based learning despite standard methods for cost calculation (Meinert et al., 2019). The reason for this variance is likely because the skills required to create instructional learning design and to capture costs are different, and educators are not trained in cost accounting methods. The analytical framework for this investigation is based on the cost analysis methods underpinning education economic evaluation developed by Levin (Levin, McEwan, Belfield, Bowden, \& Shand, 2017). Defining core costs is critical to performing further economic evaluations, though it is important to note that the scope of this research is limited to cost identification and not further economic analysis (eg, cost-benefit analysis, cost-effectiveness analysis, cost-utility analysis, and cost-feasibility analysis). 


\subsubsection{Data Collection Procedures}

Evidence to Be Expected:

To validate the costs reported in the actual budget (which was an actual cost report), at least 2 separate sources confirming the final reported amount were sought (eg, for a reported incurred cost for staff, timesheets were reviewed to match hours to costs, task completion, and assignment in a project plan). These data comparisons increased the likelihood that reported data were accurate.

\section{Events to Be Observed:}

Although the course implementation was observed and additional studies completed investigating the education effect, the scope of this study was centered on the cost decision making, and the way production affected cost delivery. Therefore, the observation scope for this study focused on reported costs and the way these correlated data to time actuals.

\section{Documentation to Be Reviewed:}

The project budget, actual costs, and timesheets were reviewed for this study. Although there will be a review of the completed course and observation of the way the course uptake is completed, the latter shall be excluded from this study. A traceability log was maintained in Microsoft Excel linking the research questions to data sources and the study findings.

\subsubsection{Study Framework}

This investigation was structured via a six-stage process for case study investigations (Yin, 2017) to identify the implementation and delivery costs associated with the production of an MOOC.

Table 1. Case study framework

\begin{tabular}{l|l}
\hline Stage & Outcome \\
\hline Plan & Case description and linking of case approach to investigation outcomes. \\
\hline Design & $\begin{array}{l}\text { Construction of research design and linkage of research questions, data, and } \\
\text { criteria for evaluation and synthesis. }\end{array}$ \\
\hline Prepare & Draft, execution, and approval of study protocols. \\
\hline Collect & $\begin{array}{l}\text { Data collection strategy executed from a realist perspective to capture the decision } \\
\text { making of the course designers centered }\end{array}$ \\
\hline Analyze & $\begin{array}{l}\text { Data extracted into categories for review and analyzed for variance calculation. } \\
\text { Data analysis centers on } 3 \text { cost categories in the design of the preproduction } \\
\text { budget submitted to the funder. }\end{array}$ \\
\hline Share & $\begin{array}{l}\text { The findings of the variance calculation and synthesis of analysis of reasons } \\
\text { leading to variation were presented in a report for publication in a peer-reviewed } \\
\text { journal (This study). }\end{array}$ \\
\hline
\end{tabular}




\section{COST MEASUREMENTS IN PRODUCTION AND DELIVERY OF A MASSIVE OPEN ONLINE COURSE (MOOC) FOR TEACHING THE RELATIONSHIP BETWEEN HUMAN HEALTH AND CLIMATE CHANGE: A CASE STUDY}

\section{Stage 1: Plan}

This was the second study to investigate cost analysis in the production of eLearning (Meinert et al., 2019). On consideration of study design, we focused on a case method because the study was focused on eLearning implementation which would not undergo experimentation on influencing actions of the course designers; the principal objective was to analyse what happened and determine the reasons for impact on the course implementation. A governing proposition established and reinforced from previous research (Meinert et al., 2019) was that there would be significant variance in the actual costs to the budgeted cost of the course; the critical variance in this implementation context, however, would be the way in which designing for an MOOC varied from a targeted Small Private Online Course implementation.

The study question centred on capturing the cost elements for the creation, design, and deployment of the online course. The literature suggests a good understanding of costs and their associated impact on production and delivery in online learning (Al-Shorbaji, Atun, Car, Majeed, \& Wheeler, 2015), so the research question was focused on providing evidence to understand this relationship better.

\section{Stage 2: Design}

The research design was structured to investigate how the total costs for the production and delivery of the MOOC were calculated. In line with previous findings and evidence from the literature on the insufficient nature of budgets as means of determining that the total cost of education delivery (Levin, McEwan, Belfield, Bowden, \& Shand, 2017; Meinert, Reeves, Eerens, Banks, Maloney, Rivers, Ilic, Walsh, Majeed, Car, 2019), the core proposition of the investigation was focused on measuring an expected variance between cost of delivery from budget in course production, influenced by the nature of iterative development of eLearning and potential underreporting of costs. To test this principle, the 'ingredients method' (Levin et al., 2017) was used to capture all the components of the cost of production.

Table 2. Case study research design (Yin, 2017)

\begin{tabular}{|c|c|c|c|c|}
\hline Study question & Proposition & $\begin{array}{c}\text { The case } \\
\text { (definition) }\end{array}$ & $\begin{array}{l}\text { Logic linking } \\
\text { data to the } \\
\text { proposition }\end{array}$ & $\begin{array}{l}\text { Criteria for } \\
\text { interpreting } \\
\text { findings }\end{array}$ \\
\hline $\begin{array}{l}\text { How are the } \\
\text { total costs for } \\
\text { the production } \\
\text { and delivery of } \\
\text { a massive open } \\
\text { online course } \\
\text { calculated? }\end{array}$ & $\begin{array}{l}\text { Actual costs and } \\
\text { budgeted costs will } \\
\text { vary due to the } \\
\text { iterative nature of } \\
\text { eLearning and } \\
\text { underreporting of } \\
\text { staff costs }\end{array}$ & $\begin{array}{l}\text { Determination } \\
\text { and } \\
\text { measurement } \\
\text { costs }\end{array}$ & $\begin{array}{l}\text { Cost analysis of } \\
\text { project costs, } \\
\text { actual cost, and } \\
\text { underreported } \\
\text { costs }\end{array}$ & $\begin{array}{l}\text { Variance } \\
\text { calculation } \\
\text { of the } \\
\text { project } \\
\text { budget }\end{array}$ \\
\hline
\end{tabular}


IADIS International Journal on WWW/Internet

Three tests (Yin, 2017) were used to ensure and validate the quality of the study research design.

Test 1: Construct validity

The purpose of a construct validity test is to show that data sources are triangulated and validated from multiple sources (Yin, 2017). Multiple sources of cost data and reporting data were used

to validate that data sources were an accurate record of what occurred: (1) The project budget created at the project commencement, (2) the actual cost report submitted at the completion of the project, (3) the timesheet log of hours captured by each team resource, (4) a third-party work-log

for course production and monitor of billable hours recorded charged to the program, (5) external audit reports on the course construction, and (6) review of notes from monthly reviews of budget spend. The final case report was reviewed, and feedback gathered from the course designers; feedback was provided and reviewed by the research team to ensure implementation accuracy.

Test 2: External validity

The purpose of an external validity test is to demonstrate how principal findings can find applicability in other use cases (Yin, 2017). Application of Levin's ingredients method for education intervention analysis, and use of standard costing and variance calculation activity-based costing

methods demonstrated a common analytic framework that is transportable to other studies.

\section{Test 3: Reliability}

The purpose of the reliability test is to show how the activities of the study are repeatable (Yin, 2017). To achieve this test, a study protocol was used and formed the governing basis for the study.

\section{Stage 3: Prepare}

A study protocol modified from the previous cost investigation was used to manage the study process. Levin et al's (2017) model for cost measurement was used to analyse budget vs. actual spending. This model implements an activity-based costing standard accountancy approach, which assigns costs as they are consumed per implementation area (Kaplan, 1994, 104; Mak \& Roush, 1994, 93; Mak \& Roush, 1996, 141).

\section{Stage 4: Collect}

The data collection strategy was executed from a realist perspective to capture the financial decision making of the course designers in order to avoid interference in the course delivery. However, it did not incorporate a relativist perspective with regard to stakeholders, through further qualitative investigation. This decision was made to avoid interference in course delivery. In order to control selectivity and reporting bias, data was triangulated following construct validity tests. A traceability log was maintained linking the study questions to the relevant data sources and the study findings.

\section{Stage 5: Analyse}

Data analysis centred on three cost categories in the design of the pre-production budget submitted to the funder. 
COST MEASUREMENTS IN PRODUCTION AND DELIVERY OF A MASSIVE OPEN ONLINE COURSE (MOOC) FOR TEACHING THE RELATIONSHIP BETWEEN HUMAN HEALTH AND CLIMATE CHANGE: A CASE STUDY

Category A: Concept and measurement of costs

The pre-production budget was analysed for the following ingredient categories: 1) personnel, 2) estate charges, 3) equipment and materials, 4) indirect costs, and 5) stakeholder costs. The initial budgets did not reflect time for stakeholder costs (effort from third-party lecturers); therefore, this was captured as the additional time that was monitored in the study (and added for budget variance calculation), as there was no value for this in the data submitted to the funder.

Category B: Placing values on ingredients

With the full cost of production defined, values were associated with each ingredient sub-category to reflect the chargeable cost (including direct and indirect costs).

Category C: Analysing costs

The course was analysed for the one-time cost of the project because it was designed as a one-year project (initially); therefore, the variance from implementation costs was the critical variable under consideration. Variance calculation of the budget to the incurred costs was reviewed on a fortnightly basis for tracking and completed as a summary report at project completion.

The variance calculation formula is as follows: Variance $=$ Actual spending - Budgeted spending.

Stage 6: Share

The findings of the variance calculation and analysis of reasons leading to variation were presented in a draft case report to the course design team. Feedback was gathered on analysis and results. The key findings for this report were prepared for publication for a peer-review journal (this manuscript).

\subsubsection{Project Management}

The case implemented project management methods for the organization of crucial deliverables and tasks in their design and integrated learning design methodology in different ways. The analysis, design, development, implementation, and evaluation (ADDIE) model, and course planning was structured along each of these design stages were integrated.

\subsection{Results}

\subsubsection{Course Production Costs}

Category A: Concept and measurement of costs

Table 3. Ingredient categories

\begin{tabular}{l|l}
\hline Ingredient categories & Cost components \\
\hline Personnel & University staff \\
\hline Estate charges & IT services charges \\
\hline Equipment and materials & $\begin{array}{l}\text { Course production equipment, application development costs for } \\
\text { the creation of software to support the MOOC }\end{array}$ \\
\hline Indirect costs & University overheads \\
\hline Stakeholder costs & Staff for third-party subject matter consultancy \\
\hline
\end{tabular}


IADIS International Journal on WWW/Internet

Category B: Placing values on ingredients

Upon completion of the analysis of the ingredients of the course production, the initial budget was created and submitted to the funder.

Table 4. Ingredient Costs of the Climate Change and Public Health MOOC

Cost in 2017

\begin{tabular}{lc}
\hline Personnel & $£ 43,646$ \\
Estate charges & $£ 2,345$ \\
Equipment and materials & $£ 3,255$ \\
Indirect costs & $£ 11,725$ \\
Stakeholder costs & $£ 25,999$ \\
\hline
\end{tabular}

Category C: Analysing costs

Budget variance calculation

The actual spending had a negative variance from budgeted spending in Personnel, Equipment and materials and Stakeholder costs, with the total cost of production being $113 \%$ the budgeted amount. The most significant negative variance was in stakeholder costs, where the total time for external lecturers and subject matter experts (as sub-contracted third parties) to deliver cost work was significantly underbudgeted, by $190 \%$. The reason for this underestimate was that videos had to be reshot twice and the amount of time allocated to retrieve stakeholders and complete associated course updates had a dramatic impact on the budget. The second-largest negative variance was in personnel; the cost variance was directly related to the additional production time required for the video reshoots, in addition to the iteration of the development of the platform. During the course delivery, there was change in facts relating to course content, also requiring a reshoot; due to the nature of this course, this material will require constant updating to keep it timely and relevant. Additionally, the course implementation online learning provider also switched through in the project from edX to FutureLearn (edX and FutureLearn are MOOC learning management systems), requiring a rework of previously completed tasks. Finally, equipment and materials were also underestimated with a $133 \%$ overage, having to do with additional software required for video editing and additional workstations gathered to deal with additional editing required in the course development. 
COST MEASUREMENTS IN PRODUCTION AND DELIVERY OF A MASSIVE OPEN ONLINE COURSE (MOOC) FOR TEACHING THE RELATIONSHIP BETWEEN HUMAN HEALTH AND CLIMATE CHANGE: A CASE STUDY

Table 5. Ingredient Costs variance calculation

\begin{tabular}{l|l|l|l|l|} 
& Budget & Actual & Variance & Var \% \\
\hline Personnel & $£ 43,646$ & $£ 88,456$ & $£ 44,810$ & $103 \%$ \\
Estate charges & $£ 2,345$ & $£ 2,345$ & $£ 0$ & $0 \%$ \\
Equipment and materials & $£ 3,255$ & $£ 7,599$ & $£ 4,344$ & $133 \%$ \\
Indirect costs & $£ 11,725$ & $£ 11,725$ & $£ 0$ & $0 \%$ \\
Stakeholder costs & $£ 25,999$ & $£ 75,332$ & $£ 49,333$ & $190 \%$ \\
\hline & & & & \\
& $£ 86,970$ & $£ 185,457$ & $£ 98,487$ & $113 \%$ \\
\hline
\end{tabular}

The construction of the cost ingredients and subsequent cost analysis underwent three validation tests:

A. Construct validity test: Multiple sources of cost data and reporting data were used to validate the accuracy of data sources as a record of what occurred: 1) the project budget created at the project commencement, 2) the actual cost report submitted at the completion of the project, 3) the timesheet log of hours captured by each team resource, 4) a third-party work-log for course production and monitor of billable hours recorded charged to the program, 5) external audit reports on the course construction, and 6) review of notes from monthly reviews of budget spending. The final case report was reviewed, and feedback gathered from the course designers (BS, MT); feedback was provided and reviewed by the research team to ensure implementation accuracy.

B. External validity test: The repetition of a model used in prior research (Meinert et al. 2019), application of Levin's ingredients method for education intervention analysis and use of standard costing and a variance calculation (horizontal budget analysis) demonstrated a common analytic framework which is transportable to other studies.

C. Reliability test: To achieve this test, a study protocol was used and formed the governing basis for the study.

\subsubsection{Participant Information}

Nine-hundred and sixty-eight learners participated in the MOOC from November to December 2017. Of the 968 learners, $17 \%$ completed the course. The course completion ratio was in-line with completion rates for MOOCs ( $\mathrm{Li} \&$ Wan, 2016, pp. 503-505), where despite a high uptake of initial learners, completion of course activity ranges from $8 \%$ to $15 \%$. 


\section{CONCLUSION}

\subsection{Principal Findings}

While the course was delivered and reported to the funder on the original budget, the actual cost of delivery had a $113 \%$ overrun. Despite developing an extremely rigorous project management methodology to avoid time and cost overruns, the production team were faced with several challenges that led them to expend far more effort than they were compensated for and than was planned. The project benefited from in-kind work by university staff with permanent positions. The team was not able to slip timelines to allow for reduction of effort over a more extended period, resulting in an additional effort towards the end of each delivery of the project plan. The negative variance in the project budget demonstrates critical lessons in the implementation of this eLearning type. In reviewing these case results, four principal findings were derived influencing the production budget and adherence to plan:

1. Resource task estimation and management

While the project employed a rigorous project management approach, this activity was based on overall milestones and not linking sub-activities to the time estimate required per task. Because there was not tracking to this level, it was difficult for the project manager to know when tasks were going significantly over budget and then how to alter subsequent tasks to compensate for these changes. A key lesson learned from the implementation in retrospective task analysis was the importance of tracking tasks at this level to allow for better adherence to the overall schedule.

\section{Contingency planning}

Three project events had a significant impact on the planned delivery schedule: the change in learning platform from edX to FutureLearn, the need to redo a series of video shoots due to issues with the lighting of one of the cameras, and the loss of principal staff member in the development of the course production. The original budget did not account for any contingency scenarios in the course planning, which meant that when these events occurred, it created automatic overages in the amount of time allocated for the course delivery that has an ultimate impact on the anticipated effort for the delivery of the project.

3. Third-party resource management

The project made use of several sub-contractors in order to speed up delivery of the course. These projects were billed on a time and materials basis and when the project overran, the associated costs of the delivery of the project had an impact on the project budget. An alternative model for the third-party development could be fixed-price outcome-based projects, such that the core project does not need to incur overruns for delivery in the execution of tasks. Of course, this shifts the basis of charge from the project to the third party, but different commercial management of these resource costs will control spending in the primary project. 


\section{COST MEASUREMENTS IN PRODUCTION AND DELIVERY OF A MASSIVE OPEN ONLINE COURSE (MOOC) FOR TEACHING THE RELATIONSHIP BETWEEN HUMAN HEALTH AND CLIMATE CHANGE: A CASE STUDY}

\section{Need for an update of course materials}

The public health content and environmental content within the course indicated a need for continuing updates of the course content. While the costs for the production of the course did not capture these incremental changes, this costing would be necessary to capture the total costs of this deployment type.

\subsection{Strengths and Limitations}

The strengths of this study are that it provided a rigorous examination of the implementation of eLearning via a Massive Open Online Course. The use of MOOCs for disseminating information to encourage behavioural change to address a global issue like climate change has broad applicability and reuse. The study leveraged previous investigations into eLearning cost variance calculation by the core research team (Meinert et al., 2019) and implemented management accountancy methods which have been purpose-built for cost evaluation of learning (Levin et al., 2017). The study design was reinforced through a detailed review of real-time project decisions and activities through regular checkpoints of financial data with the core stakeholders, leading to additional data sources to reference in a cost review of data analysed in the project implementation.

We noted two primary limitations with the study. The first is that we did not use a further qualitative investigation of decisions by survey or interview of the course designers in order to conclude course impact. Incorporating such data could have provided further insight as to decision making. Due to the time constraints of the execution and delivery of this study, it was not possible to incorporate such an examination into the study design; however, such additional data points would have made for more detailed data into issues and considerations of this course type. The second limitation is that there was not costing completed on the required updates to implement the course; this multi-year costing would be essential to capture the total costs of the delivery necessary in eLearning of rapidly changing health content.

\subsection{Further Research}

The outputs of this study, in addition to the process of execution and reflection on both strengths and limitations, suggest three possible areas for future research:

1. Standards for Costing Economic Evaluations of MOOC Implementations

Limited economic evaluations are conducted on MOOCs, most likely because educators focus on content delivery and educational effect rather than creating cost evidence. This study has created an extension of existing costing methods and demonstrated how it can be applied to MOOCs, allowing future researchers to reuse this approach to create consistent costing data, which could be subsequently benchmarked. With a growing evidence base of MOOC cost data, this could also promote further research into various forms of economic evaluation, to create possible business cases for future investment in MOOCs, should value be demonstrated.

2. Integration of Project Management, Instructional Design Methods, and Costing This study observed benefits in the combination of project management methods and instructional design methods; further research investigating ways of adopting existing 
IADIS International Journal on WWW/Internet

instructional design methods with project management methodologies and linking these methods with cost management approaches could

help address the high investment cost required in MOOCs.

3. Cost and Value Perceptions of Students and Educators

Using improved cost data from the approaches in this research, further research could attempt to identify perceptions of cost and value by comparing the perspectives of students and educators.

\subsection{Summary Perspectives}

eLearning in the form of MOOCs provides an opportunity to engage a large audience to disseminate information, which could be critical in promoting awareness of crucial topics. The ability to reach vast audiences and create engagement on course content provides the capability to leverage the efficiencies in the delivery of content. The key challenges in the development of this learning involve the associated planning required and the ability to deal with issues in the delivery of the course content. Such issues that can have an impact on the project can have a dramatic impact on the course implementation, thus altering the planned budget in course delivery. Factors accounting for the project management and associated cost tracking of the delivery of the development of this type of eLearning are necessary to capture the costs associated with this learning content accurately.

\section{ACKNOWLEDGEMENT}

Boris Serafimov and Mel Toumazos provided detailed data contributing to the study in their design, development, and deployment of the online course. This project was supported by the European Institute of Innovation and Technology - EIT Health Knowledge and Innovation Community.

\section{REFERENCES}

Al-Shorbaji, N., Atun, R. A., Car, J., Majeed, A., \& Wheeler, D. E. (Eds.). (2015). eLearning for undergraduate health professional education: a systematic review informing a radical transformation of health workforce development. World Health Organization.

Glanz, K., Rimer, B. K., \& Viswanath, K. (Eds.). (2008). Health behavior and health education: Theory, research, and practice. John Wiley \& Sons.

Hollands F, Tirthali D. (2014). Resource requirements and costs of developing and delivering MOOCs. Int Rev Res Open Distr Learn 2014 Oct 3;15(5):114-133. [doi: 10.19173/irrodl.v15i5.1901]

Joshi A, \& Perin D. M. P. (2012). Gaps in the existing public health informatics training programs: A challenge to the development of a skilled global workforce. Perspect Health Inf Manag 2012; 9:1-13

Kaplan, R. S. (1994). Flexible budgeting in an activity-based costing framework. Accounting Horizons, 8(2), 104. 


\section{COST MEASUREMENTS IN PRODUCTION AND DELIVERY OF A MASSIVE OPEN ONLINE COURSE (MOOC) FOR TEACHING THE RELATIONSHIP BETWEEN HUMAN HEALTH AND CLIMATE CHANGE: A CASE STUDY}

Levin, H. M., McEwan, P. J., Belfield, C., Bowden, A. B., \& Shand, R. (2017). Economic evaluation in education: Cost-effectiveness and benefit-cost analysis. SAGE publications.

Li, Q., \& Wan, F. (2016, July). A Case Study of the Characteristics of MOOCs Completers: Taking an Online Professional Training MOOC for Example. In 2016 IEEE 16th International Conference on Advanced Learning Technologies (ICALT) (pp. 503-505). IEEE.

Mak, Y. T., \& Roush, M. L. (1994). Flexible budgeting and variance analysis in an activity-based costing environment. Accounting Horizons, 8(2), 93.

Mak, Y. T., \& Roush, M. L. (1996). Managing activity costs with flexible budgeting and variance analysis. Accounting Horizons, 10(3), 141.

Meinert E, Eerens J, Banks C., Car J. (2019). A case study examining the cost measurements in production and delivery of a Small Private Online Course (SPOC) for teaching administrative staff to engage with young patients. (In review).

Meinert E, Reeves S, Eerens J, Banks C, Maloney S, Rivers G, Ilic D, Walsh K, Majeed A, Car J (2019), Exploring the cost of eLearning within the field of health professions education: key findings from a Systematic Scoping Review. JMIR Preprints. 11/02/2019:13681 (In review)

Milligan, C., Littlejohn, A., \& Margaryan, A. (2013). Patterns of engagement in connectivist MOOCs MERLOT Journal of Online Learning and Teaching, 9(2).

Perris K. Massive Open Online Course (MOOC) on MOOCs: Course Evaluation. (2015). Vancouver, BC: Commonwealth of Learning; 2015 Feb. URL: http://oasis.col.org/bitstream/handle/11599/568/MOOConMOOC\%20Evaluation\%20Report_webversion $\% 20 \% 281 \% 29$.pdf? sequence $=1 \&$ isAllowed=y (accessed 25 Oct 2019)

Smeda N, Dakich E, Sharda N. (2014). The effectiveness of digital storytelling in the classrooms: a comprehensive study. Smart Learning Environments 2014;1.

Swim J, Clayton S, Doherty T, et al. (2009). Psychology and global climate change: addressing a multi-faceted phenomenon and set of challenges. Washington, DC: American Psychological Association, 2009. http://www. apa. org/ science/ about/ publications/ climatechange.pdf. (accessed 25 Oct 2019)

Veletsianos, G., \& Shepherdson, P. (2016). A systematic analysis and synthesis of the empirical MOOC literature published in 2013-2015. The International Review of Research in Open and Distributed Learning, 17(2).

Watts, N., Amann, M., Arnell, N., Ayeb-Karlsson, S., Belesova, K., Berry, H., et al. (2018). The 2018 report of the Lancet Countdown on health and climate change: shaping the health of nations for centuries to come. The Lancet, 392(10163), 2479-2514.

World Health Organisation. (2016). Preventing disease through healthy environments: a global assessment of the burden of disease from environmental risks. http://www. who. int/ quantifying ehimpacts/publications/ preventing- disease/ en/ (accessed 25 Oct 2019).

Wuebbles, D. J., Fahey, D. W., Hibbard, K. A., DeAngelo, B., Doherty, S., Hayhoe, K., et al. (2017) Climate Science Special Report: A Sustained Assessment Activity of the US Global Change Research Program. US Global Change Research Program: Washington, DC, USA, 669.

Yin, R. K. (2017). Case study research and applications: Design and methods. Sage publications. 